\title{
LAJU PERTUMBUHAN DAN KELANGSUNGAN HIDUP LAMUN HASIL TRANSPLANTASI DI PERAIRAN TELUK KENDARI
}

\author{
The Growth Rate and Survival of Seagrass Transplants in Kendari Bay Waters
}

\author{
Andi Muhammad Syawal ${ }^{1}$, Ira ${ }^{2}$, dan La Ode Alirman Afu ${ }^{3}$ \\ ${ }^{1}$ Mahasiswa Jurusan Ilmu Kelautan, \\ Fakultas Perikanan dan Ilmu Kelautan, Universitas Halu Oleo. \\ Jl. H.E.A Mokodompit Kampus Hijau Bumi Tridharma Anduonohu Kendari 93232, Telp/Fax: (0401) 3193782 \\ ${ }^{2}$ Surel: irafpikunhalu@gmail.com \\ ${ }^{3}$ Surel: alirmanotsudari@yahoo.co.id
}

\begin{abstract}
Abstrak
Transplantasi lamun merupakan salah satu upaya untuk mengatasi degradasi ekosistem padang lamun. Tujuan penelitian ini untuk mengetahui laju pertumbuhan dan kelangsungan hidup lamun hasil transplantasi di Perairan Teluk Kendari. Penelitian ini dilaksanakan di Perairan Teluk Kendari (stasiun 1) dan Bungkutoko (stasiun 2) selama delapan bulan, yaitu sejak bulan Agustus 2018 sampai Mei 2019. Metode transplantasi yang digunakan adalah metode polybag dan plugs dengan jenis lamun Enhalus acoroides dan Thalassia hemprichii. Parameter lingkungan yang diperoleh saat penelitian, yakni salinitas $35 \%$, pH 6-7, suhu $30-31^{\circ} \mathrm{C}$, substrat berlumpur dan berpasir, kedalaman perairan $180-220 \mathrm{~cm}$, kecerahan 85 $100 \%$, nitrat $0,0233-0,0534 \mathrm{mg} / \mathrm{L}$, dan fosfat $0,0013-0,0025 \mathrm{mg} / \mathrm{L}$. Hasil penelitian menunjukkan bahwa laju pertumbuhan lamun hasil transplantasi tertinggi berada pada stasiun 1 dengan jenis lamun E. acoroides dengan metode polybag sebesar rata-rata $1,25 \mathrm{~mm}$ dan tingkat laju pertumbuhan lamun hasil transplantasi terendah berada pada stasiun 2 dengan jenis $T$. hemprichii dengan metode plugs sebesar rata-rata $0,20 \mathrm{~mm}$. Tingkat keberhasilan lamun hasil transplantasi tertinggi berada pada stasiun 2 dengan jenis lamun E. acoroides yang menggunakan metode polybag sebesar $68 \%$ dan tingkat keberhasilan lamun hasil transplantasi terendah berada pada stasiun 1 dengan jenis lamun E. acoroides yang menggunakan metode plugs sebesar $16 \%$.
\end{abstract}

Kata Kunci: Laju pertumbuhan, Lamun, Teluk Kendari, Transplantasi.

\begin{abstract}
Seagrass transplantation is an effort to overcome the degradation of seagrass ecosystems. The purpose of this study was to determine the growth rate and survival of transplanted seagrasses in Kendari Bay Waters. This research was carried out in Kendari Bay Waters (station 1) and Bungkutoko (station 2) for eight months, from August 2018 to May 2019. The transplant method used was polybag and plugs with seagrass species Enhalus acoroides and Thalassia hemprichii. The environmental parameters found during the study were salinity $35 \%$, $\mathrm{pH} 6-7$, temperature $30-31{ }^{\circ} \mathrm{C}$, muddy and sandy substrate, water depth $180-220 \mathrm{~cm}$, brightness $85-100 \%$, nitrate $0,0233-0,0534 \mathrm{mg} / \mathrm{L}$, and phosphate $0,0013-0,0025 \mathrm{mg} / \mathrm{L}$. The results showed that the highest growth rate of seagrass transplants was at station 1 with $E$. acoroides seagrass species by polybag method for an average of $1,25 \mathrm{~mm}$ and the lowest seagrass growth rate at transplantation station 2 with $T$. hemprichii by method plugs for an average of $0,20 \mathrm{~mm}$. The highest rate of seagrass success in transplants was at station 2 with $E$. acoroides seagrass using the polybag method at $68 \%$, and the lowest success rate of seagrasses was at station 1 with E. acoroides seagrass using the plugs method of $16 \%$.
\end{abstract}

Keywords: Growth rate, Kendari Bay, Seagrass, Transplantation.

\section{Pendahuluan}

Lamun adalah tumbuhan berbunga yang sudah sepenuhnya menyesuaikan diri untuk hidup terbenam di dalam laut. Tumbuhan ini terdiri dari rhizoma, daun, dan akar. Rhizoma merupakan batang yang terbenam dan merayap secara mendatar serta berbuku-buku. Pada buku-buku tersebut tumbuh batang pendek yang tegak ke atas, berdaun dan berbunga serta tumbuh pula akar. Dengan rhizoma dan akar inilah tumbuhan tersebut dapat menancapkan diri dengan kokoh di dasar laut.

Secara ekologis padang lamun memiliki peranan penting bagi ekosistem. Lamun merupakan sumber pakan bagi invertebrata, tempat tinggal bagi biota perairan dan melindungi mereka dari serangan predator. Lamun juga menyokong rantai makanan dan penting dalam proses siklus nutrien serta sebagai pelindung pantai dari ancaman erosi ataupun abrasi. Ekosistem padang lamun memiliki diversitas dan densitas fauna yang tinggi karena gerakan daun lamun dapat 
menangkap larva invertebrata dan makanan tersuspensi pada kolom air. Tumbuhan lamun merupakan satu-satunya tumbuhan berbunga dan berpembuluh (vascular plant) yang sudah sepenuhnya menyesuaikan diri hidup terbenam di dalam air laut.

Padang lamun merupakan ekosistem yang memiliki peran penting bagi lingkungan pesisir. Penurunan luas padang lamun di dunia merupakan akibat dari tekanan lingkungan baik alami maupun hasil aktivitas manusia. Transplantasi merupakan salah satu cara untuk merehabilitasi kondisi padang lamun yang mengalami kerusakan.

Transplantasi lamun adalah memindahkan dan menanam di tempat lain, dengan cara mencabut kemudian dipindahkan ke tempat lain atau daerah lain dengan substrat yang sama pada habitat awalnya. Transplantasi merupakan salah satu cara untuk memperbaiki atau mengembalikan habitat yang telah mengalami kerusakan pada kondisi awalnya (Azkab, 1999).

Perairan Teluk Kendari merupakan perairan semi tertutup yang terdiri atas Teluk Kendari bagian dalam dan bagian luar Akbar (2014). Teluk Kendari sebagai salah satu wilayah pesisir memiliki potensi sumberdaya perairan dan fungsi pendukung kehidupan yang sangat penting. Sebagai sumberdaya perairan, Teluk Kendari merupakan habitat bagi sejumlah organisme yang hidup di dalamnya, antara lain ikan, organisme makrofita, organisme dasar (bentos), hutan mangrove, maupun padang lamun (Irawati, 2013).

Oleh karena itu, dengan adanya penelitian ini diharapkan dapat memberikan kontribusi berupa adanya ekosistem baru di daerah perairan Teluk Kendari. Lokasi penelitian dilakukan di dua lokasi stasiun di daerah perairan disekitaran kawasan Teluk Kendari dengan metode transplantasi plugs dan polybag.

\section{Bahan dan Metode}

Penelitian ini telah dilaksanakan pada bulan Agustus 2018 - Mei 2019 di Perairan Teluk Kendari, Provinsi Sulawesi Tenggara. Lokasi transplantasi lamun dilakukan di dua stasiun, yaitu di bagian dalam teluk dan pada bagian luar teluk, sedangkan lokasi pengambilan (donor) lamun dibagian Luar Teluk (Bungkutoko). Analisis substrat dan analisis nitrat dan fosfat dilakukan di
Laboratorium Unit Produktivitas Lingkungan Perairan Fakultas Perikanan dan Ilmu Kelautan.

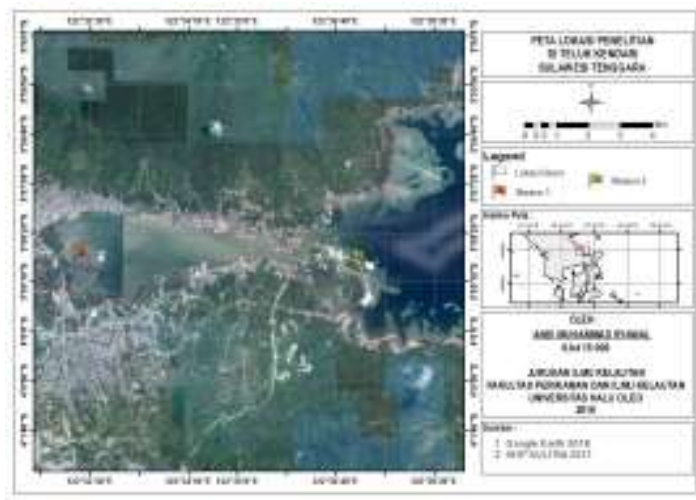

Gambar 1. Peta Lokasi Penelitian

Prosedur penelitian meliputi tahapan penentuan stasiun penelitian, pemilihan jenis lamun, teknik pengambilan bibit, pemilihan metode penanaman, penandaan daun lamun dan analisis data. Pemilihan lokasi untuk kegiatan transplantasi lamun dilakukan pada kawasan perairan Teluk Kendari. Penentuan stasiun penelitian berdasarkan perbedaan kondisi ekosistem teluk.dengan kondisi kawasan tidak memiliki padang lamun.

Stasiun 1 : Berada dibagian dalam teluk. Penentuan titik penanaman lamun transplantasi pada sekitaran kawasan masjid Al-Alam yaitu area perairan Teluk Kendari (bagian dalam) yang tidak memiliki ekosistem lamun. Dengan titik koordinat 3058'39,14'LS-122032'23,01'BT.

Stasiun 2 : Berada pada bagian luar teluk (Bungkutoko) dengan kondisi kawasan yang memiliki ekosistem lamun, penentuan titik penanaman lamun transplantasi yaitu pada sekitaran area reklamasi dimana masih didapatkan ekosistem lamun. Dengan titik koordinat 3058'52,17'LS-122036'46,99'BT.

Pemilihan jenis lamun yang akan ditransplantasi yaitu dilakukan dengan cara melihat terlebih dahulu jenis lamun yang dominan bisa ditemukan pada area pengambilan donor. Jenis lamun yang dipilih ada dua yaitu lamun jenis E. acoroides dan $T$. hemprichii. E. acoroides adalah jenis lamun yang memiliki bentuk fisik paling besar dibanding spesies lamun yang lain. Daunnya berwarna hijau pekat, panjang dan lebar seperti sabuk. Lebar daun $\pm 3 \mathrm{~cm}$. Panjang daun berkisar antara $\pm 30 \mathrm{~cm}-150 \mathrm{~cm}$. Sedangkan T. hemprichii adalah jenis lamun yang paling banyak dijumpai, biasa tumbuh 
dengan jenis lain dan dapat tumbuh hingga kedalaman 25 meter, sering dijumpai pada substrat berpasir. Kedua jenis lamun ini banyak ditemukan disekitaran area Perairan Bungkutoko.

Pengambilan bibit donor diambil saat kondisi perairan dalam keadaan rendah, hal ini memudahkan dalam proses pengambilan dan pemilihan bibit lamun yang akan ditransplantasi. Jenis lamun yang dipilih untuk transplantasi adalah jenis lamun $E$. acoroides dan $T$. hemprichii yang banyak ditemukan di Perairan Bungkutoko (bagian luar) Teluk Kendari. Pengambilan bibit lamun dengan menggunakan skop (difungsikan sebagai pembuat cekungan pada substrat disekitar bibit lamun), adapun caranya sebagai berikut:

1. Pilih lokasi yang memiliki tingkat populasi lamun yang tinggi (banyak).

2. Skop yang telah disiapkan ditancapkan kedalam substrat sampai lamun terlepas dengan akar-akarnya.

3. Pilih lamun yang akan dijadikan cikal bakal bibit.

4. Pilah jenis bibit lamun supaya memudahkan saat proses penanaman nantinya.

5. Masukkan bibit yang telah dipilih kedalam box berisi air dan hindari kontak langsung dengan matahari agar bibit lamun tidak mudah layu.

Metode transplantasi yang digunakan adalah metode plugs dan polybag. Lamun diambil lengkap dengan akar dan rhizomanya dari alam kemudian ditanam sedalam $\pm 30 \mathrm{~cm}$ dan diberi jarak $10 \mathrm{~cm}$ tiap lubang lamun transplantasi, kemudian ditutup substrat yang sama. Sebelum penanaman, lubang dipersiapkan terlebih dahulu, kemudian lamun donor dibenamkan ke dalam lubang tersebut sedemikian rupa sehingga tertanam dalam substratnya yang kokoh.

Metode penanaman yang digunakan adalah polybag dan plugs. Metode polybag yaitu bibit lamun diambil lengkap dengan akar dan rhizomanya serta sedimennya dengan menggunakan kantong polybag kemudian ditanam pada substrat, dan metode plugs yaitu bibit lamun diambil lengkap dengan akar dan rizhomanya serta sedimennya kemudian ditanam langsung pada substrat.

Penandaan daun lamun yang akan diukur laju pertumbuhannya yaitu dilakukan dengan cara memilih pucuk daun lamun. Pucuk daun lamun kemudian dilubangi pada pangkal daun. Usahakan lubang penandaan tidak terlalu besar, untuk menghindari daun lamun tidak terluka yang dapat mempengaruhi laju pertumbuhannya.

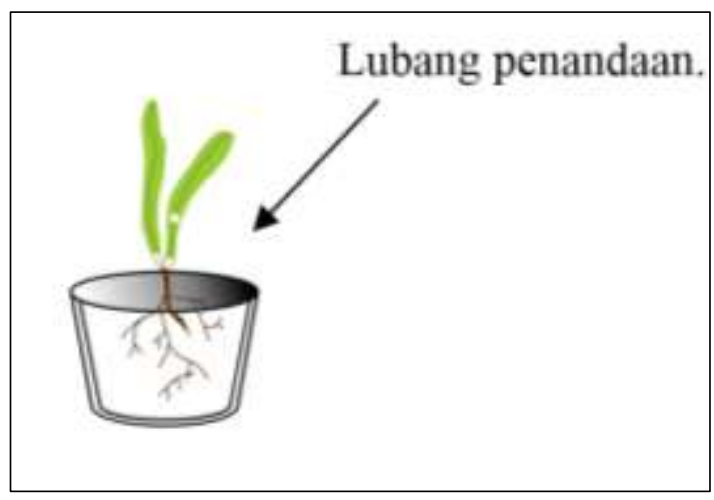

\section{Gambar 2. Sketsa Ilustrasi Metode Penandaan (Marking Method).}

Analisis data yang digunakan untuk menjawab rumusan masalah (1) tentang bagaimana laju pertumbuhan lamun hasil transplantasi di Perairan Teluk Kendari? dan rumusan masalah (2) tentang bagaimana tingkat keberhasilan lamun hasil transplantasi di Perairan Teluk Kendari? adalah analisis deskriptif. Analisis deskriptif adalah analisis yang dilakukan untuk menilai karakteristik dari sebuah data. Karakterisitik itu banyak sekali, antara lain: nilai Mean, Median, Sum, Variance, Standar error, standar error of mean, mode, range atau rentang, minimal, maksimal, skewness dan kurtosis. Adapun data yang digunakan untuk menganalisis adalah:

Analisis pertumbuhan lamun yang ditransplantasi dihitung dengan rumus Denison (1990) :

Laju pertumbuhan $=(\mathrm{Lt}-\mathrm{Lo}) / \Delta \mathrm{t}$

Keterangan :

Lo = panjang daun pada pengukuran awal (mm)

$\mathrm{Lt}=$ panjang daun lamun telah pengukuran waktu $\mathrm{t}(\mathrm{mm})$

$\Delta \mathrm{t}=$ selang waktu pengukuran (hari)

Tingkat keberhasilan lamun transplantasi. Analisis data tingkat keberhasilan lamun transplantasi berupa analisis komparatif, yakni membandingkan data setiap minggunya pada masing-masing metode transplantasi. Dihitung dengan rumus pertumbuhan daun lamun sebagai berikut (Badria, 2007):

$\mathrm{Kt}=(\mathrm{at}-\mathrm{bt}) / \mathrm{T}$

Keterangan :

$\mathrm{Kt}=$ Pertumbuhan lamun $\mathrm{t}$ (mm/hari). 
$\mathrm{T}=$ Waktu interval pengamatan (hari).

at $=$ Panjang total daun hari ke-t (mm).

$\mathrm{bt}=$ Panjang total daun atas lubang penandaan hari ke-t $(\mathrm{mm})$.

Rate.

Kelangsungan Hidup (SR) Survival

Angka kelangsungan hidup dapat dihitung dengan rumus (Royce, 1972):

$\mathrm{SR}=\mathrm{Nt} / \mathrm{N}_{0} \mathrm{X} 100$

Keterangan :

$\mathrm{SR}=$ Tingkat kelangsungan hidup (SR) (\%).

$\mathrm{Nt}=$ Jumlah unit transplantasi pada waktu $\mathrm{t}$ (bulan).

$\mathrm{N}_{0}=$ Jumlah unit transplantasi pada waktu awal atau $\mathrm{t}=0(\mathrm{~mm})$.

\section{Hasil dan Pembahasan}

Berdasarkan hasil penelitian menunjukkan bahwa Perairan Teluk Kendari bagian dalam (Stasiun 1) tempat lamun transplantasi memiliki keberhasilan pertumbuhan rendah dibandingkan (Stasiun 2) Perairan Bungkutoko, hal ini menunjukkan bahwa kondisi lingkungan yang tidak memiliki ekosistem lamun tingkat keberhasilan transplantasinya rendah. Pada stasiun 1 memiliki substrat berlumpur dengan kandungan nitrat $0,0534 \mathrm{mg} / \mathrm{L}$ dan fosfat $0,0013 \mathrm{mg} / \mathrm{L}$, dan berdekatan dengan aliran sungai wanggu yang mengarah ke laut. Stasiun 2 memiliki substrat berpasir dengan kandungan nitrat $0,0233 \mathrm{mg} / \mathrm{L}$ dan fosfat $0,0025 \mathrm{mg} / \mathrm{L}$. Sebagai produser primer, kontribusi padang lamun sangat bergantung kepada struktur komunitasnya Supriadi (2005). Adapun faktor lingkungan yang mempengaruhi laju pertumbuhan lamun transplantasi adalah $\mathrm{pH}$, kedalaman perairan, dan kecerahan.

Lamun E. acoroides dan T. hemprichii yang ditanam di Perairan Teluk Kendari bagian dalam (Stasiun 1) yang tidak memiliki ekosistem lamun ternyata mengalami pertumbuhan. Ini menandakan bahwa lamun jenis E. acoroides dan T. hemprichii memiliki pertumbuhan dan kelangsungan hidup dengan tingkat toleransi yang tinggi. Hal ini sesuai dengan pernyataan Arthana (2004) bahwa $E$. acoroides adalah jenis lamun yang memiliki toleransi tinggi. Lamun jenis T. hemprichii ditemukan hidup dari salinitas 3,5-60\%, kisaran optimum untuk pertumbuhan $\mathrm{T}$. hemprichii dilaporkan dari salinitas $24-35 \%$ o (Dwindaru, 2010).

Laju pertumbuhan lamun transplantasi jenis E. acoroides lebih tinggi daripada lamun jenis T. hemrpichii (Tabel 1). Hal ini dipengaruhi oleh faktor lingkungan yang berbeda, dimana pada stasiun 1 memiliki perairan yang keruh sedangkan pada stasiun 2 memiliki perairan yang jernih. Cahaya merupakan faktor pembatas pertumbuhan dan produksi lamun di perairan yang keruh Hutomo (1997). Hal ini mengganggu lamun untuk melakukan proses fotosintesis untuk kelangsungan hidupnya, tetapi untuk lamun jenis $E$. acoroides itu memiliki tingkat toleransi yang tinggi.

Tabel 1. Laju Pertumbuhan dan Kelangsungan Hidup Lamun Transplantasi (mm).

\begin{tabular}{lccccccccc}
\hline \multirow{2}{*}{$\begin{array}{l}\text { Lenis } \\
\text { Lamun/Metode }\end{array}$} & \multicolumn{7}{c}{ Laju Pertumbuhan (mm/hari) } \\
\cline { 2 - 9 } & V1 (hari ke-112) & V2 (hari ke-119) & V3 (hari ke-126) & \multicolumn{2}{c}{ Rata-rata } \\
\cline { 2 - 10 } & st. 1 & st. 2 & st. 1 & st. 2 & st. 1 & st. 2 & st. 1 & st. 2 \\
\hline A. E. acoroides & & & & & & & & \\
1. metode plugs & 0.48 & 0.77 & 0.68 & 0.93 & 0.71 & 0.95 & 0.62 & 0.89 \\
2. metode polybag & 1.17 & 1.19 & 1.25 & 1.27 & 1.25 & 1.27 & 1.22 & 1.25 \\
\hline B. T.hemprichii & & & & & & & & \\
1. metode plugs & 0.12 & 0.02 & 0.40 & 0.22 & 0.44 & 0.37 & 0.32 & 0.20 \\
2. metode polybag & 0.27 & 0.02 & 0.35 & 0.25 & 0.39 & 0.35 & 0.34 & 0.21 \\
\hline
\end{tabular}


Tabel 2. Persentase Kelangsungan Hidup Lamun Transplantasi bulan November 2018 dan Februari 2019

\begin{tabular}{cccccc}
\hline \multirow{2}{*}{ Bulan } & & \multicolumn{4}{c}{ Metode Transplantasi } \\
\cline { 3 - 6 } & Stasiun & \multicolumn{3}{c}{ Plugs } & \multicolumn{2}{c}{ Polibag } \\
\cline { 3 - 6 } & & $\begin{array}{l}\text { Enhalus } \\
\text { acoroides }\end{array}$ & $\begin{array}{l}\text { Thalassia } \\
\text { hemprichii }\end{array}$ & $\begin{array}{l}\text { Enhalus } \\
\text { acoroides }\end{array}$ & $\begin{array}{l}\text { Thalassia } \\
\text { hemprichii }\end{array}$ \\
\hline \multirow{2}{*}{ November } & 1 & $16 \%$ & $64 \%$ & $36 \%$ & $60 \%$ \\
\cline { 2 - 6 } & 2 & $28 \%$ & $56 \%$ & $68 \%$ & $60 \%$ \\
\hline \multirow{2}{*}{ Februari } & 1 & $100 \%$ & $100 \%$ & $100 \%$ & $100 \%$ \\
\cline { 2 - 6 } & 2 & $100 \%$ & $100 \%$ & $100 \%$ & $100 \%$ \\
\hline
\end{tabular}

Tabel 3. Parameter Lingkungan Perairan Teluk Kendari.

\begin{tabular}{clcc}
\hline \multirow{2}{*}{ No. } & \multirow{2}{*}{ Parameter Lingkungan } & \multicolumn{2}{c}{ Stasiun Penelitian } \\
\cline { 3 - 4 } & & Stasiun 1 & Stasiun 2 \\
\hline 1 & Salinitas (\%o) & 35 & 35 \\
2 & $\mathrm{pH}$ & 6 & 7 \\
3 & Suhu $\left({ }^{\circ} \mathrm{C}\right)$ & 30 & 31 \\
4 & Substrat & Berlumpur & Berpasir \\
5 & Kedalaman Perairan $(\mathrm{cm})$ & 220 & 180 \\
6 & Kecerahan $(\%)$ & 85 & 100 \\
7 & Nitrat $(\mathrm{mg} / \mathrm{L})$ & 0,0534 & 0,0233 \\
8 & Fosfat $(\mathrm{mg} / \mathrm{L})$ & 0,0013 & 0,0025 \\
\hline
\end{tabular}

E. acoroides adalah jenis lamun yang memiliki toleransi tertinggi. Lamun jenis ini memiliki daun yang lebih tebal, lebar, dan panjang, sehingga memiliki ruang fotosintesa yang lebih besar per individunya (Arthana, 2004). Jenis ini memiliki panjang daun hingga 1 meter. Karena itu apabila terjadi kekeruhan di perairan dimana penetrasi cahaya terganggu sehingga proses fotosintesis terhalang. Bagi $E$. acoroides keadaan tersebut tampaknya tidak terlalu bermasalah karena daunnya yang panjang hingga dapat mencapai dekat permukaan air, sehingga proses fotosintesis tetap dapat berjalan.

Laju pertumbuhan lamun transplantasi jenis E. acoroides dan lamun transplantasi jenis T. hemprichii pada stasiun 1 dan stasiun 2 dengan menggunakan metode polybag lebih tinggi daripada metode plugs (Tabel 2). Hal ini disebabkan kantong polybag melindungi bibit yang berada dalam kantong dari arus. Kelebihan daripada metode polybag yaitu melindungi lamun transplantasi dari arus dan ombak. Hal ini sesuai dengan pernyataan Apramilda dan Riesna (2011), Metode polybag memiliki kelebihan yaitu bibit lamun yang didonorkan lebih terlindung dan kokoh.

Laju pertumbuhan lamun transplantasi jenis E. acoroides pada stasiun 2 lebih besar daripada stasiun 1. Stasiun 2 memiliki kecerahan $100 \%$. Hal ini sesuai pernyataan Irawati et al (2013), nilai kecerahan tertinggi berada pada mulut teluk. Hal ini sangat memungkinkan lamun untuk melakukan proses fotosintesis secara optimal. Berbeda dengan lamun transplantasi jenis $T$. hemprichii pada stasiun 1 lebih besar daripada stasiun 2. Dimana pada stasiun 1 memiliki kecerahan $85 \%$. Masuknya muatan bahan tersuspensi yang terbawa melalui aliran sungai yang terbawa arus mengakibatkan kecerahan menjadi rendah Winnarsih et al (2016). T. hemprichii adalah salah satu jenis lamun yang memiliki toleransi yang cukup tinggi terhadap lingkungan yang memiliki tingkat kecerahan rendah. Hal ini sesuai dengan pernyataan Rohmimohtarto dan Juwana (2001), T. hemprichii merupakan jenis lamun yang memiliki daya tahan yang baik terhadap kecerahan. 
Kelangsungan hidup lamun transplantasi dilihat dari jumlah keseluruhan bibit lamun yang bertahan hidup. Persentase keberhasilan lamun transplantasi pada bulan November 2018 pada 2 stasiun yaitu pada stasiun 1 jenis $E$. acoroides dengan menggunakan metode plugs yaitu $16 \%$ dengan jumlah bibit yang hidup adalah 4 bibit, dan lamun transplantasi jenis E. acoroides dengan menggunakan metode polybag yaitu $36 \%$ dengan jumlah bibit yang hidup adalah 9 bibit. Sedangkan lamun transplantasi jenis $T$. hemprichii dengan menggunakan metode plugs yaitu 64\% dengan jumlah bibit yang hidup adalah 16 bibit, dan lamun transplantasi jenis $T$. hemprichii dengan menggunakan metode polybag yaitu $60 \%$ dengan jumlah bibit yang hidup adalah 15\% dengan jumlah bibit yang hidup adalah 15 bibit.

Persentase keberhasilan lamun transplantasi di stasiun 1 jenis T. hemprichii lebih tinggi daripada lamun jenis $E$. acoroides. Hal ini sesuai dengan pernyataan Rohmimohtarto dan Juwana (2001), $T$. hemprichii merupakan jenis lamun yang memiliki daya tahan yang baik terhadap kecerahan. Ini menandakan bahwa lamun jenis $T$. hemprichii adaptif atau mudah menyesuaikan diri terhadap gangguan lingkungan yang disebabkan oleh kecerahan perairan. Substrat berlumpur menyebabkan perairan keruh sehingga mempengaruhi kecerahan perairan. Hal ini sesuai dengan pernyataan Putra (2017), kekeruhan disebabkan oleh substrat lumpur berpasir yang teraduk.

Kurangnya intensitas cahaya matahari yang masuk ke perairan akibat tingginya TSS yang terjadi di Teluk Kendari bisa memberikan efek berupa meningkatnya tingkat kekeruhan yang selanjutnya berdampak negatif terhadap ekosistem perairan. Tingginya nilai total suspended solid pada daerah aliran Sungai Wanggu dan daerah kawasan perhotelan disebabkan masukan bahan-bahan tersuspensi yang berasal dari daratan yang terbawa oleh aliran sungai, bahan-bahan tersuspensi ini masuk melalui aliran Sungai Wanggu dan bermuara di Teluk Kendari Winnarsih et al (2016). Hal ini juga sesuai dengan penelitian yang dilakukan oleh Irawati et al (2011) di Perairan Teluk Kendari yang menyatakan bahwa nilai total suspended solid di perairan tersebut tergolong tinggi yaitu $294-391 \mathrm{mg} / \mathrm{L}$.
Persentase keberhasilan lamun transplantasi di stasiun 2 jenis $E$. acoroides lebih tinggi daripada lamun transplantasi jenis T. hemprichii. Hal ini disebabkan pada stasiun 2 memiliki substrat yang berpasir dengan suhu lingkungan $31^{\circ} \mathrm{C}$ ditambah oleh faktor alam (musim kemarau) sangat mempengaruhi lamun transplantasi untuk beradaptasi dan melakukan proses pertumbuhan. Lamun jenis E. acoroides memiliki tipe morfologi tubuh yakni daun, rimpang, dan akar yang lebih besar daripada $T$. hemprichii yang memudahkannya untuk melakukan penetrasi terhadap lingkungan. Hal ini sesuai dengan pernyataan Apramilda dan Riesna (2011), lamun jenis E. acoroides memiliki kisaran laju pertumbuhan daun yang lebih besar karena E. acoroides memiliki morfologi tubuh yakni daun, rimpang, dan akar yang besar. Lamun transplantasi jenis $E$. acoroides dengan metode polybag memiliki nilai persentase keberhasilan sebesar 68\% dengan jumlah bibit yang hidup adalah 17 bibit, dan pada lamun transplantasi jenis $E$. acoroides dengan menggunakan metode plugs memiliki persentase keberhasilan sebesar $28 \%$ dengan jumlah bibit yang hidup adalah 7 bibit.

Lamun transplantasi jenis $T$. hemprichii dengan menggunakan metode plugs memiliki persentase keberhasilan sebesar 56\% dengan jumlah bibit yang hidup adalah 14 bibit, dan lamun transplantasi jenis T. hemprichii dengan menggunakan metode polybag memiliki persentase keberhasilan sebesar $60 \%$ dengan jumlah bibit yang hidup adalah 15 bibit. Metode polybag memiliki tingkat kelangsungan hidup yang lebih besar dibandingkan dengan metode plugs dikarenakan pada metode polybag bibit lamun transplatasi lebih kokoh dikarenakan kantong polibag menahan substrat dari gerukan arus dan ombak. Ini menandakan bahwa penggunaan metode polybag pada transplantasi sangat membantu karena kantong polybag menjadi wadah yang kuat untuk tempat tumbuh bagi lamun transplantasi. Metode polybag memiliki kelebihan yaitu bibit lamun yang didonorkan lebih terlindung dan kokoh (Apramilda dan Riesna, 2011).

Persentase keberhasilan lamun transplantasi jenis E. acoroides dan $T$. hemprichii pada bulan Februari 2019 menggunakan metode plugs dan polybag adalah $100 \%$ (Tabel 3). Nilai kelangsungan 
hidup yang diperoleh menunjukkan bahwa lamun transplantasi pada Perairan Teluk Kendari sudah berhasil mengalami proses adaptasi terhadap habitat barunya.

Laju pertumbuhan lamun transplantasi pada Perairan Teluk Kendari ini masuk kategori berhasil karena bibit lamun dapat bertahan dan tumbuh dengan baik meski diawal mengalami proses adaptasi yang berfluktuasi. Lamun dapat beradaptasi di daerah yang tidak memiliki ekosistem lamun walaupun tingkat keberhasilan yang lebih rendah.

\section{Kesimpulan}

Berdasarkan hasil dan pembahasan maka dapat ditarik kesimpulan sebagai berikut:

1. Laju pertumbuhan lamun hasil transplantasi tertinggi berada pada 1 stasiun (perairan yang tidak memiliki lamun) dengan jenis lamun E. acoroides dengan metode polybag sebesar rata-rata $1,25 \mathrm{~mm}$ dan tingkat laju pertumbuhan lamun hasil transplantasi terendah berada pada stasiun 2 (area yang memiliki lamun) dengan jenis $T$. hemprichii dengan metode plugs sebesar rata-rata $0,20 \mathrm{~mm}$.

2. Tingkat keberhasilan lamun hasil transplantasi tertinggi berada pada stasiun 2 (perairan yang memiliki lamun) dengan jenis lamun $E$. acoroides yang menggunakan metode polybag sebesar 68\% dan tingkat keberhasilan lamun hasil transplantasi terendah berada pada stasiun 1 (perairan yang tidak memiliki lamun) dengan jenis lamun E. acoroides yang menggunakan metode plugs sebesar $16 \%$.

\section{Daftar Pustaka}

Akbar, J., Bahtiar, dan Ishak. 2014. Studi Morfometrik Kerang Kalandue (Polymesoda erosa) di Hutan Mangrove Teluk Kendari. Jurnal Mina Laut Indonesia. Vol. 4. Nomor $01 \mathrm{p}(1-12)$. ISSN 2303-3959.

Alaerts G., dan Santika, S., S. 1984. Metode Penelitian Air. Usaha Nasional. Surabaya. Indonesia.

Apramilda dan Riesna. 2011. Status Temporal Komunitas Lamun Dan Keberhasilan Transplantasi Lamun Pada Kawasan Rehabilitasi Lamun Di Pulau Pramuka
Dan Harapan, Kepulauan Seribu, Provinsi DKI Jakarta ; IPB.

Arthana, I, W, 2004. Jenis dan Kerapatan Padang Lamun di Pantai Sanur Bali. Jurnal Lingkungan Hidup. Bumi Asih, Vol. 4 (2)

Azizah, E., Nasution S., Ghalib, M. 2017. Biomass And Density Of Seagrass Enhalus acoroides In The Village Waters Jago-Jago Of Tapanuli Tengah North Sumatera Province. Student And Lecturer in Fisheries and Marine Science Faculty, Riau University, Pekanbaru. 1104114897.

Azkab, 1999. Pedoman Inventarisasi Lamun. Oseana, XXIV (1); 1-16.

Badria, S. 2007. Laju Pertumbuhan Daun Lamun (Enhalus acoroides) pada Dua Substrat yang Berbeda di Teluk Banten. Skripsi. Fakultas Perikanan dan Ilmu Kelautan, IPB. Bogor.

Denison, D. R. 1990. Wiley Series On Organizational Assessment And Change. Corporate Culture And Organizational Effectiveness. Oxford, England: John Wiley And Sons.

Dwindaru, 2010. Skripsi. Variasi Spasial Komunitas Lamun Dan Keberhasilan Transplantasi Lamun Di Pulau Pramuka Dan Kelapa Dua, Kepulauan Seribu, Provinsi DKI Jakarta. Departemen Sumberdaya Perairan. Fakultas Perikanan dan Ilmu Kelautan. Institut Pertanian Bogor.

Febriyantoro, Riniatsih I., Endrawati H. 2013. Rekayasa Teknologi Transplantasi Lamun (Enhalus acoroides) Di Kawasan Padang Lamun Perairan Prawean Bandengan Jepara. Jurnal Penelitian Kelautan. Volume 1 Nomor 1. Hal. 1-10.

Fuad Harwadi. 2018. Teknik Reklamasi. Universitas Borneo Tarakan.

Hanianti N., Karlina I., dan Irawan H. 2016. Laju Pertumbuhan Jenis Lamun enhalus acoroides Dengan Teknik Transplantasi Polybag dan Spring Anchor Pada Jumlah Tunas Yang Berbeda Dalam Rimpang Di Perairan Bintan.

Hemminga MA \& Duarte CM. 2000. Seagrass ecology. Cambridge University Press. United Kingdom.

Hutomo M. 1997. Struktur Komunitas Padang Lamun Perairan Indonesia. P. 54-61. In: 
Inventarisasi dan Evaluasi Potensi Laut-Pesisir II geologi, kimia, biologi, dan ekologi. Prosiding Kongres Biologi Indonesia XV. Universitas Indonesia. Jakarta.

Hutomo M. 1999. Proses Peningkatan Nutrient Mempengaruhi Kelangsungan Hidup Lamun. LIPI. Jakarta.

Irawati, N. Adiwilaga, E., M., dan Prawtiwi, N., T., M. 2013. Hubungan Produktivitas Primer Fitoplankton Dengan Ketersediaan Unsur Hara Dan Intensitas Cahaya Di Perairan Teluk Kendari Sulawesi Tenggara. Jurnal Biologi Tropis. Vol. 13. No. 2. ISSN: 1411-9587.

Kebijakan Reklamasi Di Wilayah Pesisir : Tujuan, Manfaat, dan Efek. 2016. Menteri Kelautan dan Perikanan.

Kiswara W. 1997. Inventarisasi dan Evaluasi Sumberdaya Pesisir: Struktur Komunitas Padang Lamun di Teluk Banten. Makalah Kongres Biologi Indonesia XV. Jakarta. Indonesia.

Kiswara W. 2004. Kondisi Padang Lamun (seagrass) di Teluk Banten 1998-2001.

Pusat Penelitian Oseanografi Lembaga Ilmu Pengetahuan Indonesia.

Kiswara, 2009. Kandungan Hara dalam Air antara Air dan Air Permukaan Padang Lamun Pulau Barrang Lompo dan Gusung Talang, Sulawesi Selatan. Dalam Prosiding Seminar Nasional. Jakarta.

Lanuru, 2011. Bottom Sediment Characteristics Affecting the Success of Seagress (Enhalus acoroides) Transpalantation in the Westcoast of South Biological an Environmental Conference Enginering. IPCBEE vol. 20 (2011), Singapore.

Lee, K. S., Park, S. R., Kim, Y. K., 2007. Effect of Irradiance, Temperature And Nutriens On Growth Dynamic of Seagrass: a review. J Exp Bio Ecol 35: 144-175.

McKenzie L. 2008. Seagrass watch. Prosiding of Workshop for Mapping Seagrass Habitats in North East Arnhem Land, Northern Territory. 18-20 Oktober. Cairns, Australia. Hal: 9-16.

Nybakken JW. 1992. Biologi Laut: suatu pendekatan ekologis. [Terjemahan dari: Marine biologi: an ecological approach]. Eidman HM, Bengen DG,
Hutomo M, \& Sukardjo S (penerjemah). PT Gramedia. Jakarta. Xiii $+459 \mathrm{hlm}$.

Phillips, R., C. 1980. Planting Guidelines for Seagrass. Costal Enginering Technical Aid No.82, U. S. Army, Corps of Engineers, Virginia.

Phillips, R., C. and E., G. Menez. 1988. Seagrasses. Smithsonion Institution Press, Washington D. C., 104 P.

Pratiwi, R. 2010. Asosiasi Krustasea di Ekosistem Padang Lamun Perairan Teluk Lampung. Jurnal Ilmu Kelautan. Vol. 15(2) 66-67. ISSN 0853-7291.

Putra, A., Husrin, S., dan Mutmainah H. 2017. Pola Sebaran Kualitas Air Berdasarkan Kesesuaian Baku Mutu Untuk Biota Laut Di Teluk Kendari Provinsi Sulawesi Tenggara. Maspari journal. 9(1):51-60.

Rahman, A., A. Nur, A., I., dan Ramli M. 2016. Studi Laju Pertumbuhan Lamun (Enhalus ecoroides) Di Perairan Pantai Desa Tanjung Tiram Kabupaten Konawe Selatan. Jurnal Sapa Laut. Vol 1 (1). 10-16. E-ISSN 2503-0396.

Rahmawati, S., Fahmi, dan Yusup, D., F. 2012. Komunitas Padang Lamun dan Ikan Pantai di Perairan Kendari, Sulawesi Tenggara. Jurnal Ilmu Kelautan. Vol. 17 (4): 190-198 ISSN 0853-7291.

Riniatsih I dan Endrawati H. 2013. Pertumbuhan Lamun Hasil Transplantasi Jenis Cymodocea rotundata di Padang Lamun Teluk Awur Jepara. Buletin Oseanografi Marina. Vol 2. 34-40.

Romimohtarto K dan Juwana S. 2001. Biologi Laut: Ilmu pengetahuan tentang biota laut. Djambatan. Jakarta. xii. + 540p.

Royce, W. F. 1972. Introduction to the Fhisery Sciences. Academic Press. Inc. New York. San Fransisco, London.

Saeni MS. 1989. Kimia Lingkungan. Departemen Pendidikan dan Kebudayaan, Ditjen Pendidikan Tinggi. Pusat Antar Universitas Ilmu Hayat. IPB. Bogor.

Short, I. T., 1987. Effect of Sediment Nutrient Seagrassses. Literature Review And Mesocoms Experiment. Marine Botani.

Short FT \& Coles RG (eds). 2001. Global Seagrass research methods. Elsevier Science BV. Amsterdam. 
Supriadi, Soedharma D., Kaswadji, R., F. 2005. Beberapa aspek pertumbuhan lamun Enhalus acoroides (Linn. F) Royle di Pulau Barrang Lompo Makassar. Biosfera 23 (1) Januari 2006.

Syukur, A., Wardiatno, Y., Muchsin, I., dan Mukhlis, M., K. 2014. Status Trofik Ikan yang Berasosiasi dengan Lamun (Seagrass) di Tanjung Luar Lombok Timur. Jurnal Biologi Tropis. Vol. 14 (2). ISSN 1411-9587.

Takaendengan, K dan Huzni, M., A. 2010. Struktur Komunitas Lamun Di Pulau Talise, Sulawesi Utara. Jurnal Oseanologi dan Limnologi di Indonesia. Volume 36(1): 85-95. ISNSN 0125-9830.

Winnarsih, Emiyarti, dan Alirman, L., O., A. 2016. Distribusi Total Suspended Solid Permukaan Di Perairan Teluk Kendari. Jurnal Sapa Laut. Vol. 1 (2). 54-59. EISSN 2503-0396.

Wulandari D., Riniatsih I., dan Yudiati E. 2013. Transplantasi Lamun Thalassia hemprichii Dengan Metode Jangkar Di Perairan Teluk Awur Dan Bandengan, Jepara. eJournal-s1.undip.ac.id. Vol. 2 (2). 30-38.

Zieman JC. 1975. Tropical Seagrass Beds and Mangrove Ecosystem: Their Interaction in the Coastal Zones of the Carribean. UNESCO. Rep. Mar. Sci., 23:6-16. 